\title{
Phycocyanin/PEG-b-(PG-g-PEI) attenuated hepatic ischemia/reperfusion-induced pancreatic islet injury and enlarged islet functionality
}

This article was published in the following Dove Medical Press journal: International Journal of Nanomedicine

\author{
Fei Tong' \\ Xiangyuan Tang ${ }^{2}$ \\ Daojun Liu² \\ 'Department of Pathology and \\ Pathophysiology, Provincial Key \\ Discipline of Pharmacology, Jiaxing \\ University Medical College, Jiaxing, \\ Zhejiang Province, PR China; \\ ${ }^{2}$ Department of Pharmaceutical \\ Chemistry, Medical College, Shantou \\ University, Shantou, PR China
}

\begin{abstract}
Background: Hepatic ischemia/reperfusion-induced pancreatic islet injury (HI/RIPII) was an important pathophysiological phenomenon in clinics. In the present study, we observed the effects of phycocyanin on HI/RIPII. However, the half-life of phycocyanin was extremely short and limited its use in vivo.

Materials and methods: In order to overcome this shortcoming, poly(ethylene glycol)- $b$ (poly(L-glutamic acid)- $g$-polyethylenimine) (PEG- $b$-(PG- $g$-PEI)) was synthesized and estimated as a nanocarrier for lengthening delivery of phycocyanin through the abdominal subcutaneous injection in rats. Phycocyanin (isoelectric point=4.3) was encapsulated with PEG- $b$-(PG- $g$-PEI) via electrostatic interactions at $\mathrm{pH} 7.4$.

Results: In vitro phycocyanin was fast and efficiently encapsulated and showing efficient loading and sustained release. In vivo the anti-HI/RIPII function of phycocyanin/PEG- $b$-(PG$g$-PEI) complex was surveyed in rats using free phycocyanin as the controls, and the results showed that phycocyanin/PEG- $b$-(PG- $g$-PEI) complex reduced HI/RIPII property and enlarged islet functionality.
\end{abstract}

Conclusion: These results suggested that PEG- $b$-(PG- $g$-PEI) might be treated as a potential phycocyanin nanocarrier.

Keywords: phycocyanin, PEG- $b$-(PG- $g$-PEI), HI/RIPII, pancreatic islets

\section{Introduction}

Hepatic ischemia/reperfusion injury (HI/RI) has been widely researched during the last decades and is closely related to the pathophysiology of numerous clinical entities following liver surgery and transplantation. ${ }^{1} \mathrm{HI} / \mathrm{RI}$ not only results in liver damage but also induces remote organ damage, especially pancreatic islet injury. ${ }^{2}$ In addition, HI/RI contains two injury phases: first damage phase $(<6$ hours $)$ and second damage phase $(>6$ hours), and many studies focus on the first damage phase rather than the second damage phase on HI/RI. ${ }^{2}$ Previous literature has reported that HI/RI can aggravate the secretion of pancreatic beta cells. ${ }^{2}$ Many factors are reported to get in touch with the pathogenesis of HI/RI. ${ }^{1}$ Overfull reactive oxygen species (ROS) engendered in the liver after ischemia/reperfusion (I/R) is one of the main mechanisms contained in HI/RI. ${ }^{3-5}$ Overfull productions of ROS induces remote organ injuries via oxidative stress, and inflammatory responses. ${ }^{6,7}$ Therefore, clearance of ROS will be a potential therapeutic method for HI/RI.

Recently studies have shown that severe hyperglycemia occurs frequently during the period of new liver opening on HI/RI, and this affects not only the patient's internal environmental stability and the success rate of surgery, but also the recovery of the patient after surgery. ${ }^{2}$ However, whether HI/RI interacts with hyperglycemia and mediates
Correspondence: Fei Tong

Department of Pathology and

Pathophysiology, Provincial Key Discipline

of Pharmacology, Jiaxing University

Medical College, Jiaxing, Zhejiang

Province 3/400I, PR China

Tel +86 I373643 I280

Email tongxuchang@163.com
International Journal of Nanomedicine 20|9:14 339-35|

339 
hypoinsulinism is still unclear. Based on the abovementioned findings, we hypothesized that phycocyanin attenuated hepatic ischemia/reperfusion-induced pancreatic isle injury (HI/RIPII) and enlarged islet functionality.

Phycocyanin as deep-sea algae extract is safe and nontoxic, and its unique medicinal function has attracted widespread attention at home and abroad, especially in the field of anti-tumor research has a certain degree of breakthrough. ${ }^{8}$ Recent research results suggest that phycocyanin has an antioxidant, anti-inflammatory, anticancer, anti-radiation role and improves immunity. ${ }^{9}$ Moreover, phycocyanin protects brain and myocardium against I/R-induced injury. ${ }^{10,11}$ However, phycocyanin treatment is limited due to its short plasma half-life and poor stability. Thus, dosing is extremely difficult and frequent injections are needed, which is inconvenient for patients and leads to low compliance. ${ }^{12}$ In this study, we are striving to identify appropriate delivery systems to encapsulate phycocyanin and ameliorate its poor stability. Here, we synthetize poly(ethylene glycol)- $b$-(poly(L-glutamic acid)- $g$-polyethylenimine) (PEG- $b$-(PG- $g$-PEI)) as a potential phycocyanin carrier. The synthesis of the PEG- $b$-(PG- $g$-PEI) polymer refers to a previous document. ${ }^{13}$ The negatively charged phycocyanin (isoelectric point $=4.3$ ) combines with the positively charged PEI block via electrostatic interactions at $\mathrm{pH} 7.4$ (shown in Scheme 1 and Figure S1). The encapsulated phycocyanin guarantees sustained release, which may augment the protective effect and bioactivity of phycocyanin. The encapsulation capacity of phycocyanin is evaluated through in vitro release. In in vivo research, we keep on assessing the sustained pharmacological effect of the phycocyanin-encapsulated PEG- $b$-(PG- $g$-PEI) which significantly attenuates HI/RIPII and enlarges islet functionality in comparison with free phycocyanin as the control.

\section{Materials and methods Materials}

PEI 600, mPEG-NH $_{2}$ (molecular weight=2,000 Da) and phycocyanin were bought from Aldrich-Sigma; L-glutamic acid was purchased from Aladdin (Shanghai, China); HIT-T15 cells was bought from Shanghai Bioleaf Biotech Co., Ltd. (Shanghai, China); other reagents and kits were purchased from Sigma-Aldrich Co., St Louis, MO, USA.

\section{Methods}

\section{Synthesis of PEG-b-(PG-g-PEI)}

PEG- $b$-(PG- $g$-PEI) was synthesized via referring to previous literature. ${ }^{13}$ First of all, we referred to our previous works to synthesize PEG- $b$-PBLG. ${ }^{14-18}$ PEI 600 was put in DMF and heated in a water bath at $40^{\circ} \mathrm{C}$. The suitable number of PEG- $b$-PBLG was mixed with a quantity of PEI/DMF fluid. The corresponsive compounds were stirred for 24 hours and dialyzed. The PEG- $b$-(PG- $g$-PEI) polymeric compounds were gained through freeze-drying, and the product was characterized via ${ }^{1} \mathrm{H}$-nuclear magnetic resonance.

\section{Cytotoxicity estimation of PEG-b-(PG-g-PEI)}

For a detailed depiction of the estimation of cytotoxicity (HIT-T15 cells were selected) of PEG-b-(PG-g-PEI), refer to our previous works. ${ }^{14-18}$

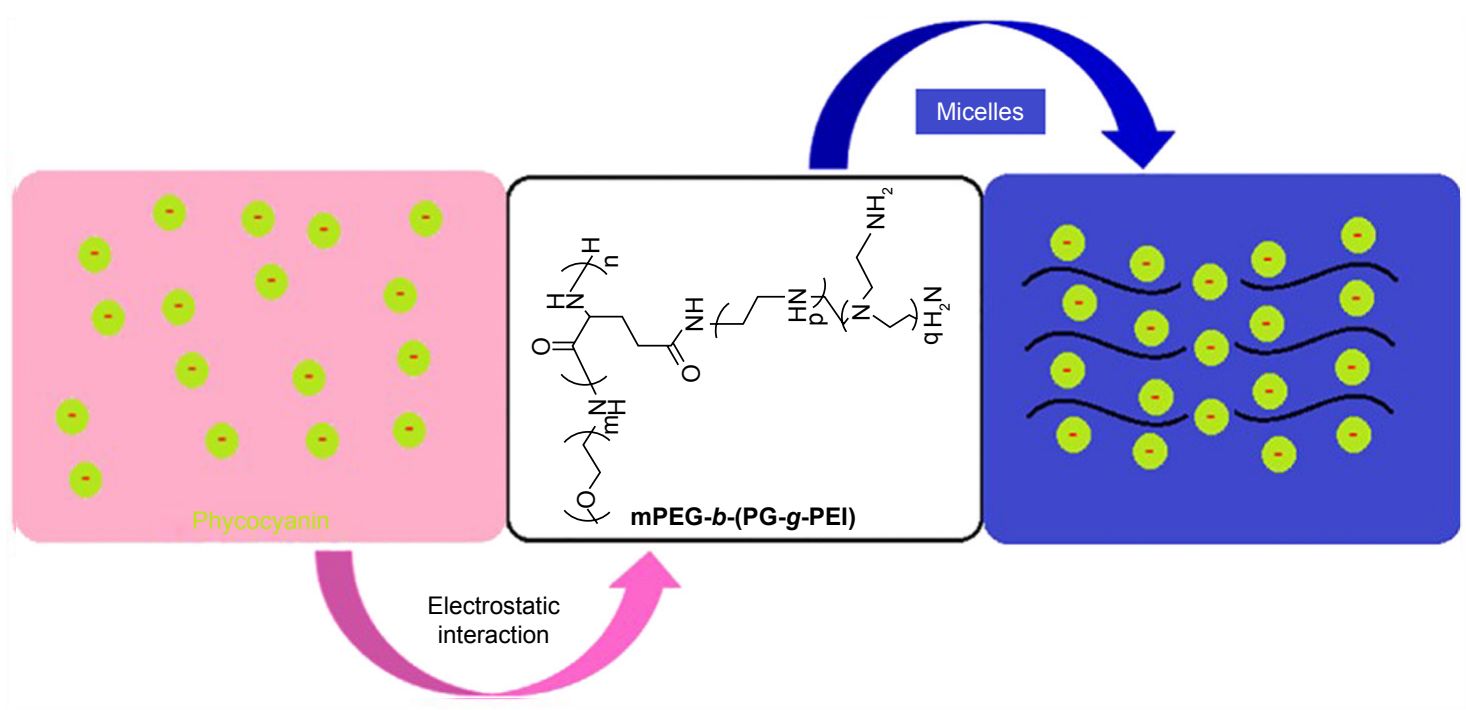

Scheme I The structure of phycocyanin/PEG-b-(PG-g-PEI).

Abbreviations: $\mathrm{mPEG}-\mathrm{NH}_{2}$, methoxy poly(ethylene glycol) amine; PEG-b-(PG-g-PEI), poly(ethylene glycol)-b-(poly(L- glutamic acid)-g-polyethylenimine). 


\section{Loading of phycocyanin via PEG-b-(PG-g-PEI)}

To evaluate the encapsulation of phycocyanin by PEG- $b$-(PG$g$-PEI), a certain amount of phycocyanin $(5 \mathrm{mg} / \mathrm{mL})$ in PBS $(\mathrm{pH}=7.2,0.01 \mathrm{mmol} / \mathrm{L})$ was mixed with PEG- $b$-(PG- $g$-PEI) in $\mathrm{PB}$ solutions and then the resulting solution was put in a dialysis bag to dialyze. The PEG- $b$-(PG- $g$-PEI)-encapsulated phycocyanin was observed through an ELISA kit, technique of particle size measurement and transmission electron microscopy (TEM).

\section{Phycocyanin release in vitro}

Release of phycocyanin from PEG- $b$-(PG- $g$-PEI) was observed by a dialysis method at $37^{\circ} \mathrm{C}$, with $5 \mathrm{~mL}$ of phycocyanin-encapsulated PEG- $b$-(PG- $g$-PEI) against a PB buffer. At a certain time interval, a given volume of the release media was dislodged and supplemented with an equal volume of fresh release media. The amount of phycocyanin released was checked via ELISA methods.

\section{Animal and surgical process of $\mathrm{HI} / \mathrm{RI}$}

Sprague Dawley rats (160-240 g) were acquired from the Jiaxing University, Medical College, Jiaxing, PR China. The procedures and care of animals were approved through the Institutional Ethics Committee of Jiaxing University, Medical College, Jiaxing, PR China. The investigations conformed to the guide for the care and use of laboratory animals published by the US National Institutes of Health (NIH Publication updated in 2011). In this research, 40 male Sprague Dawley rats were assigned to four groups (each group=10 rats): (1) Sham group; (2) I/R group: male Sprague Dawley rats were anesthetized with $1 \%$ pentobarbital sodium $(50 \mathrm{mg} / \mathrm{kg})$ through intraperitoneal injection. The abdomina were opened and livers were exposed to discover the left and median liver lobes, then clamped for 1 hour in order to cause $70 \%$ hepatic ischemia, followed by 12 hours of reperfusion; (3) phycocyanin group: phycocyanin was administrated once a day $(10 \mathrm{mg} / \mathrm{kg})$ through abdominal subcutaneous injection for 16 days prior to $\mathrm{I} / \mathrm{R}$ procedures; (4) phycocyanin/PEG- $b$-(PG-g-PEI) (phycocyanin/P) group: phycocyanin/P (10 mg/kg) was administrated once every 4 days through abdominal subcutaneous injection for 16 days prior to $\mathrm{I} / \mathrm{R}$ procedures. The blood was collected from abdominal aorta and centrifuged under $3,500 \times g$ for 20 minutes to obtain the sera. Livers and pancreatic islets of male Sprague Dawley rats were collected and stored at $-80^{\circ} \mathrm{C}$ until analysis.

\section{Histopathologic change of liver injury}

Sections $(4 \mu \mathrm{m})$ of livers were cut and stained with HE stain. The sample was blindly analyzed to observe the degree of liver injury based on the technique outlined by Yang et al and Li et al. ${ }^{19,20}$ Briefly, the liver injuries were observed based on each of the following parameters: cytoplasmic discoloration, vacuolation formation, nuclear pyknosis, nuclear fragmentation, nuclear discoloration and red cell stasis. Specifically, one whole deep coronal section was observed via microscope and graded according to the degree of injury, based on the percentage of involvement of liver. Higher score represents more severe damage, with the maximum score being 4 ( 0 , histopathological changes $<10 \% ; 1,10 \%-25 \%$; $2,25 \%-50 \% ; 3,50 \%-75 \%$; and $4,75 \%-100 \%)$. The mean score for each parameter was measured and subjected to statistical analysis.

\section{Liver function measurement}

Aminotransferase (AST) and alanine aminotransferase (ALT) activities were observed by the previous methods. ${ }^{21}$ The blood was collected after reperfusion for 12 hours and centrifuged at $3,500 \times \mathrm{g}$ for 20 minutes to obtain the sera. AST and ALT activities were observed through a standard automatic biochemistry analyzer.

\section{Histopathologic changes of pancreatic islet tissue damage}

Sections $(4 \mu \mathrm{m})$ of pancreatic islets were cut and stained with HE stain. The sample was blindly analyzed to observe the degree of pancreatic islet injury based on the technique outlined by Chuan et al. ${ }^{22}$ Briefly, the pancreatic islet damages were assessed based on each of the following parameters: the islet structure disorder and atrophy, showing irregular border and volume of pancreatic islet cells increased, morphology was abnormal and nuclear distribution was eccentric. A higher score represents more severe damage, with the maximum score being $4(0$, histopathological changes $<10 \%$; $10 \%-25 \% ; 2,25 \%-50 \% ; 3,50 \%-75 \%$; and $4,75 \%-100 \%$ ). The mean score for each parameter was observed and subjected to statistical analysis.

\section{Blood glucose, blood insulin and insulin secretion index on HI/RIPII for different groups of rats}

Blood glucose was measured via micro blood glucose meter and blood insulin was evaluated by radio immunity. ${ }^{2}$ Insulin secretion index was observed via the following formula: insulin secretion index $=20 \times$ blood insulin/(blood glucose -3.5$){ }^{23}$ 
Blood insulin and metabolic rate of glucose on hyperglycemic clamp test

Blood insulin and metabolic rate of glucose on hyperglycemic clamp test were measured by previous methods. ${ }^{2,24-27}$

The activity of superoxide dismutase (SOD) and the level of malondialdehyde (MDA) on HI/RIPII for different groups of rats

The SOD activity and MDA level of islet cells were measured by xanthine oxidase and thiobarbituric acid method via previous literature. ${ }^{28}$ Absorbance was observed at 550 and $532 \mathrm{~nm}$, respectively. Lipid peroxide levels were shown via "U" of SOD/mL and "nmol" of MDA/mL.

\section{Apoptosis evaluation}

To refer to previous literature, ${ }^{29-32}$ pancreatic islet tissue damaged was extracted, and paraffin sections preconditioning dewaxed to water, $40 \mathrm{~g} / \mathrm{L}$ paraformaldehyde fixed for 15 minutes and PBS washed for 5 minutes $\times 2$ times, $20 \mathrm{mg} / \mathrm{L}$ protease $\mathrm{K}$ solutions dissolved in Tris/HCL $(\mathrm{pH}$ 7.4-8.0) for 20 minutes at $37^{\circ} \mathrm{C}$, then PBS washed for 5 minutes $\times 3$ times and added $50 \mu \mathrm{L}$ TUNEL reaction liquid at $37^{\circ} \mathrm{C}$ for $60 \mathrm{~min}$ utes, PBS washed for 5 minutes $\times 3$ times and added $50 \mu \mathrm{L}$ POD at $37^{\circ} \mathrm{C}$ for 30 minutes, DAB colored for $5-10$ minutes and PBS washed for 5 minutes $\times 3$ times, and hematoxylin counterstain for 1 minute. Then the slices were washed, dehydrated transparent, sealed and observed; TUNEL reaction were replaced via PBS and was acted as negative control. Through light microscope observation, the normal pancreatic islet cell nuclei were light blue and apoptosis of pancreatic islet cells were deep blue. Each slice randomly selected 5 high magnification $(\times 400)$ to calculate apoptotic index: (apoptosis index, $\mathrm{AI})=($ the number of apoptotic cells/total cell number) $\times 100 \%$ and take the mean.

\section{ROS expression}

Previous methods had been referred to here. ${ }^{33-36}$ After 12 hours of reperfusion, Sprague Dawley rats were anesthetized with $1 \%$ pentobarbital sodium $(50 \mathrm{mg} / \mathrm{kg})$, and CM-H $H_{2}$ DCFDA $(100 \mu \mathrm{g})$ was injected into the pancreas circulation. After $\mathrm{CM}-\mathrm{H}_{2}$ DCFDA injection, the pancreatic islets were harvested for 45 minutes and dipped in $4 \%$ paraformaldehyde for about 24 hours. After cure with $20 \%$ sucrose for about 12 hours, the pancreatic islets were promptly frozen in liquid nitrogen. Cryostat sections were cut at $-20^{\circ} \mathrm{C}$ and the sections were placed on Star-Frost adhesive slides and air-dried for about 3 minutes. Parts were washed in PBS and stained with DAPI for fluorescence microscopy analysis in ROS qualitative assessment. ROS quantitative assessment in isolated mitochondria was implemented by the Amplex red $\mathrm{H}_{2} \mathrm{O}_{2}$ /peroxidase assay kit (Sigma-Aldrich Co., St Louis, MO, USA) through a spectrofluorometer and emission wavelengths of 544 and $590 \mathrm{~nm}$, respectively.

\section{Data analysis}

SPSS 17.0 software was used for data administration and statistical analysis. Measurement data was expressed as \pm SD. Statistical analysis was actualized via ANOVA with post-hoc testing. A $P$-value of less than $0.01(P<0.01)$ was used for statistical significance.

\section{Results}

\section{Synthesis and characterization of PEG-b- (PG-g-PEI)}

The PEG- $b$-(PG- $g$-PEI) contained a PEG block, PG and PEI (Scheme 1 and Figure S1); they were characterized via ${ }^{1} \mathrm{H}$ NMR spectra, as depicted in Figure S2A and Table 1.

\section{Cellular viability measurements}

The cell toxicity from PEG- $b$-(PG- $g$-PEI) on HIT-T15 cells was measured in 24 hours culturing and the results are shown in Figure S2C. The PEG- $b$-(PG- $g$-PEI) kept high cell toxicity even below a level as high as $250 \mu \mathrm{g} / \mathrm{mL}$.

\section{Encapsulation capacity of phycocyanin in PEG-b-(PG-g-PEI)}

Phycocyanin was efficiently encapsulated via PEG- $b$ (PG-g-PEI) at physiological $\mathrm{pH}$ via hydrophobic interaction. Phycocyanin was put in PEG-b-(PG-g-PEI) (mass ratio=1:5) and dialyzed in PB solutions. The dialysis of free phycocyanin as a control was also implemented at the same condition.

Table I Molecular weights, particle size, TEM and phycocyanin-loading capacity of PEG-b-(PG-g-PEI)

\begin{tabular}{l|l|l|l|l}
\hline Sample & Mn (kDa)/'H NMR & Particle size (nm) & TEM (nm) & Loading capacity (\%) \\
\hline P & 20.7 & 8 & 21 & NA \\
Phycocyanin/P & NA & 39 & 70 & 8.05 \\
\hline
\end{tabular}

Abbreviations: 'H NMR, 'H-nuclear magnetic resonance; Mn, number-average molecular weight; NA, not applicable; PEG-b-(PG-g-PEl), poly(ethylene glycol)-b-(Poly(Lglutamic acid)-g-polyethylenimine); TEM, transmission electron microscopy. 
To determine the encapsulation of phycocyanin in PEG$b$-(PG- $g$-PEI), the quantity of phycocyanin was measured via ELISA. The encapsulation of phycocyanin was $8.05 \%$ through calculating, as depicted in Table 1.

\section{Characterization measurement of PEG- $b$ - (PG-g-PEI) and phycocyanin/PEG-b-(PG- $g$-PEI) compounds}

The PEG- $b$-(PG- $g$-PEI) and phycocyanin/PEG- $b$-(PG- $g$-PEI) compounds were measured using a granulometer and TEM. The images of TEM were observed in Figure S2B and the particle diameters were measured with a granulometer in Figure S2D. The PEG- $b$-(PG- $g$-PEI) and phycocyanin/PEG$b$-(PG-g-PEI) compounds both showed an orbicular structure and the diameters were 21 and $70 \mathrm{~nm}$ (TEM), respectively (Table 1); the particle sizes of PEG- $b$-(PG- $g$-PEI) and phycocyanin/PEG- $b$-(PG- $g$-PEI) compounds were 8 and $39 \mathrm{~nm}$ (granulometer), respectively (Table 1).

\section{In vitro release of phycocyanin}

The phycocyanin release from PEG- $b$-(PG- $g$-PEI) was measured via dialysis method $(\mathrm{MWCO}=7 \mathrm{kDa})$ at $37^{\circ} \mathrm{C}$, with $5 \mathrm{~mL}$ of phycocyanin/PEG- $b$-(PG- $g$-PEI) against a PB solution of $0.02 \mathrm{~mol} / \mathrm{L}$ (physiological condition). The release curve of phycocyanin/PEG- $b$-(PG- $g$-PEI) was observed in Figure 1. After 2 hours, $25.16 \%$ of the phycocyanin was released from phycocyanin/PEG- $b$-(PG- $g$-PEI), showing the beginning of a burst release of exenatide. About $72.29 \%$ of

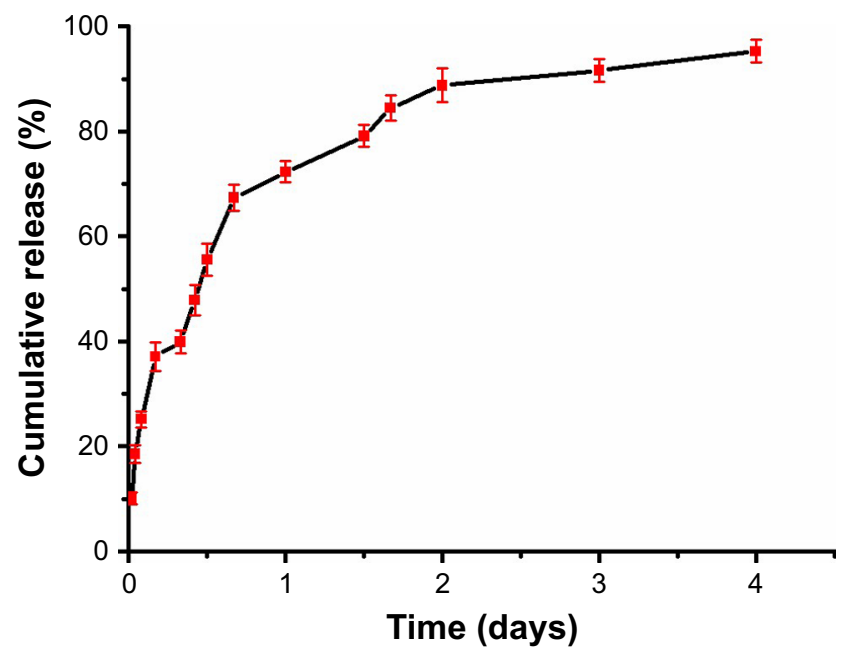

Figure I Cumulative releasing profile of phycocyanin from phycocyanin/PEG-b(PG-g-PEI).

Abbreviation: PEG-b-(PG-g-PEI), poly(ethylene glycol)-b-(poly(L-glutamic acid)-gpolyethylenimine). the phycocyanin was released after 1 day and $95.25 \%$ after 4 days, revealing biphase release profile from phycocyanin/ PEG- $b$-(PG- $g$-PEI).

\section{Histopathologic change of liver damage}

Light microscopy images of liver sections were observed in Figure 2. The hepatic lobule structure disorder, hepatic sinusoid and central veins had different degrees of blood stasis; liver blood sinus narrowed or disappeared; endothelial cells and hepatocytes were widely showing edema and degeneration, neutrophil attachment and focal necrosis; cytoplasmic discoloration, vacuolation formation, nuclear pyknosis, nuclear fragmentation, nuclear discoloration and red cell stasis were measured in histological specimen from the $\mathrm{I} / \mathrm{R}$ group (Figure $2 \mathrm{~B}$ ) but were absent in the Sham group (Figure 2A). Histological alteration was decreased in specimens from the phycocyanin group (Figure 2C) compared to the I/R group. Histological alteration was remarkably reduced in specimens from the phycocyanin/P group(Figure 2D) compared to the I/R group. The corresponding quantitative analysis was observed in Figure 2E.

\section{ALT and AST activities}

ALT and AST activities were observed after reperfusion for 12 hours (Figure 3 ) and was higher in the I/R group than in the Sham group $(P<0.01$; ALT: Sham group $43 \pm 8 \mathrm{U} / \mathrm{L}$, I/R group 604 $\$ 36 \mathrm{U} / \mathrm{L}$; AST: Sham group 92 $\pm 13 \mathrm{U} / \mathrm{L}, \mathrm{I} / \mathrm{R}$ group 1485 $\pm 96 \mathrm{U} / \mathrm{L})$. Administration of phycocyanin reduced $\operatorname{ALT}(417 \pm 25 \mathrm{U} / \mathrm{L})$ and AST $(910 \pm 101 \mathrm{U} / \mathrm{L})$ compared with ALT and AST in the $\mathrm{I} / \mathrm{R}$ group $(P<0.01)$. Administration of phycocyanin/P significantly reduced ALT $(290 \pm 31 \mathrm{U} / \mathrm{L})$ and AST $(672 \pm 84 \mathrm{U} / \mathrm{L})$ compared with ALT and AST in the I/R group $(P<0.01)$.

\section{Histopathologic change of pancreatic islets tissue damage}

Light microscopy images of pancreatic islet sections were observed in Figure 4. The islet structure disorder and atrophy showing irregular border and volume of pancreatic islets cells increased, morphology was abnormal and nuclear distribution was eccentric; they were measured in histological specimens from the I/R group (Figure 4B) but were absent in the Sham group (Figure 4A). Histological alteration was decreased in specimens from the phycocyanin group (Figure 4C) compared to the I/R group. Histological alteration was remarkably reduced in specimens from the phycocyanin/P group (Figure 4D) compared to the I/R group. The corresponding quantitative analysis was observed in Figure 4E. 

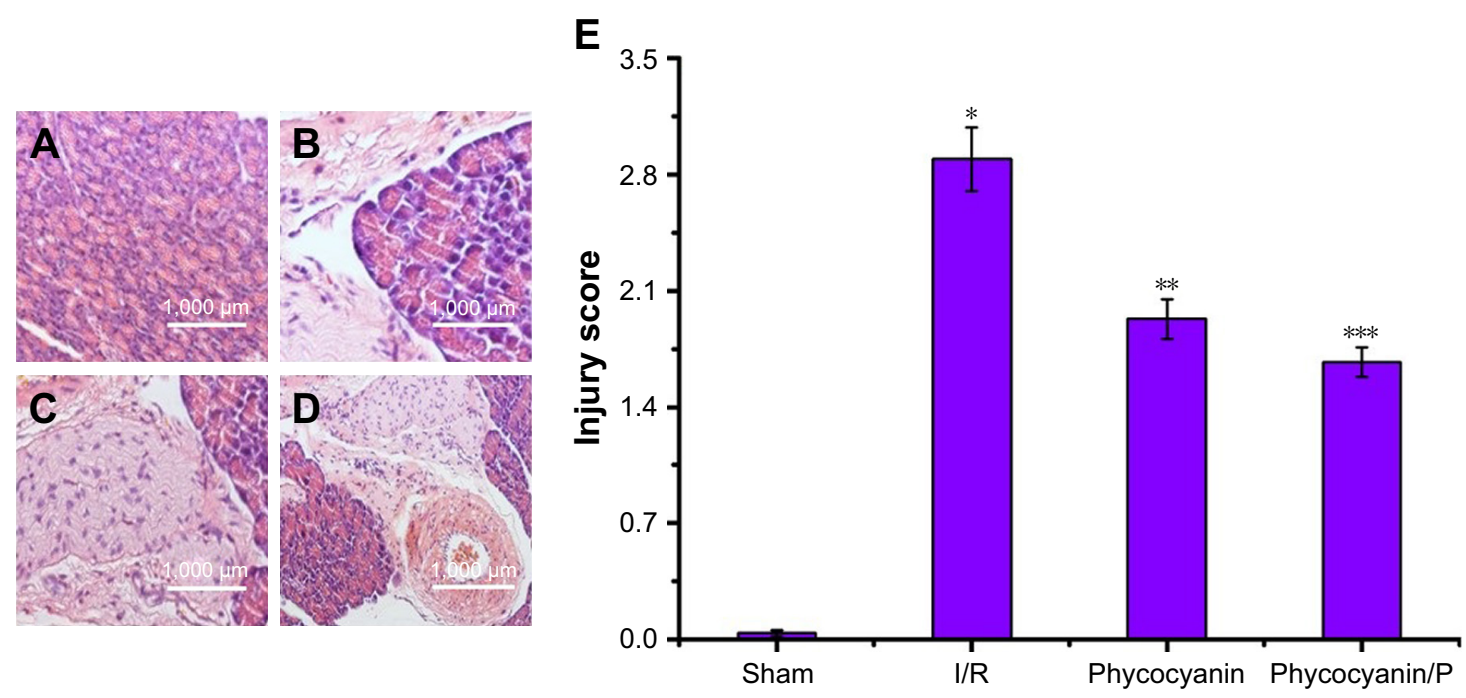

Figure 2 Histopathologic change of liver injury.

Notes: Light microscopy images $(\times 400)$ in Sham group $(\mathbf{A})$, I/R group $(\mathbf{B})$, phycocyanin group $(\mathbf{C})$ and phycocyanin/PEG-b-(PG-g-PEI) group (D), respectively. Quantitative injury scores, expressed as the mean $\pm S D$, are shown in Figure $4(E)$. *Significant increase relative to the Sham group $(P<0.0 \mathrm{I})$. $* *$ Significant decrease relative to the I/R group $(P<0.01)$. *** Significant decrease relative to the I/R group $(P<0.01)$.

Abbreviation: PEG-b-(PG-g-PEI), poly(ethylene glycol)-b-(poly(L-glutamic acid)-g-polyethylenimine).

\section{Blood glucose, blood insulin and insulin secretion index on HI/RIPII for different groups of rats}

Blood glucose was measured after reperfusion for 12 hours (Figure $5 \mathrm{~A}$ ) and was higher in the $\mathrm{I} / \mathrm{R}$ group than in the Sham group $(P<0.01$; blood glucose: Sham group $4.05 \pm 1.07 \mathrm{mmol} / \mathrm{L}$, I/R group $10.32 \pm 1.19 \mathrm{mmol} / \mathrm{L})$. Administration of phycocyanin

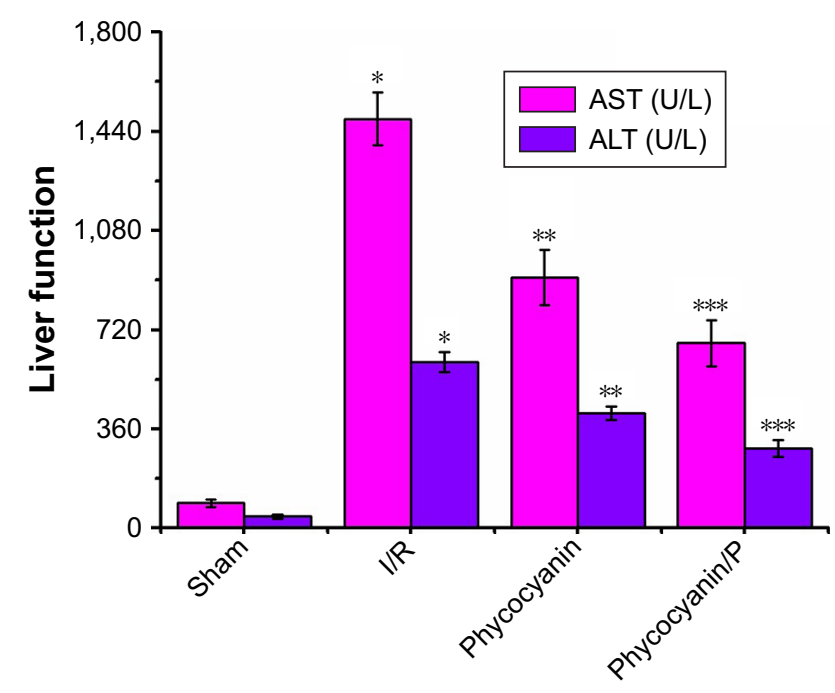

Figure 3 The activities of ALT and AST on HI/RIPII for different groups of rats. Notes: The blood of Sham, I/R, phycocyanin and phycocyanin/PEG-b-(PG-g-PEI) groups of rats were collected 12 hours after reperfusion and the activities of AST and ALT measured. Results are expressed as mean \pm SD. *Significant increase from the Sham group $(P<0.01)$. **Significant decrease from the I/R group $(P<0.01)$. $* * *$ Significant decrease from the I/R group $(P<0.0 \mathrm{I})$.

Abbreviations: I/R, ischemia/reperfusion; ALT, alanine aminotransferase; AST, aminotransferase; HI/RIPII, hepatic ischemia/reperfusion-induced pancreatic islets injury; PEG-b-(PG-g-PEI), poly(ethylene glycol)-b-(poly(L-glutamic acid)-g-polyethylenimine). reduced blood glucose $(6.14 \pm 0.88 \mathrm{mmol} / \mathrm{L})$ compared with blood glucose in the $\mathrm{I} / \mathrm{R}$ group $(P<0.01)$. Administration of phycocyanin/P significantly reduced blood glucose $(5.21 \pm 0.93 \mathrm{mmol} / \mathrm{L})$ compared with blood glucose in the $\mathrm{I} / \mathrm{R}$ group $(P<0.01)$.

Blood insulin was observed after reperfusion for 12 hours (Figure 5B) and was higher in the $\mathrm{I} / \mathrm{R}$ group than in the Sham group $(P<0.01$; blood insulin: Sham group $61.84 \pm 10.24 \mathrm{mU} / \mathrm{L}, \mathrm{I} / \mathrm{R}$ group $127.52 \pm 8.98 \mathrm{mU} / \mathrm{L})$. Administration of phycocyanin reduced blood insulin $(108.34 \pm 9.03 \mathrm{mU} / \mathrm{L})$ compared with blood insulin in the $\mathrm{I} / \mathrm{R}$ group $(P<0.01)$. Administration of phycocyanin/P significantly reduced blood insulin $(84.15 \pm 10.07 \mathrm{mU} / \mathrm{L})$ compared with blood insulin in the $\mathrm{I} / \mathrm{R}$ group $(P<0.01)$.

Insulin secretion index was checked after reperfusion for 12 hours (Figure 5C) and was lower in the I/R group than in the Sham group $(P<0.01$; insulin secretion index: Sham group $2248.73 \pm 123.45$, I/R group 373.96 \pm 97.39 ). Administration of phycocyanin increased insulin secretion index (820.76 \pm 109.24$)$ compared with insulin secretion index in the I/R group $(P<0.01)$. Administration of phycocyanin/P significantly increased insulin secretion index $(984.21 \pm 88.93)$ compared with insulin secretion index in the $\mathrm{I} / \mathrm{R}$ group $(P<0.01)$.

\section{Blood insulin and metabolic rate of glucose on hyperglycemic clamp test}

Blood insulin was observed on hyperglycemic clamp test (Figure 6A) and was lower in the $\mathrm{I} / \mathrm{R}$ group than in 


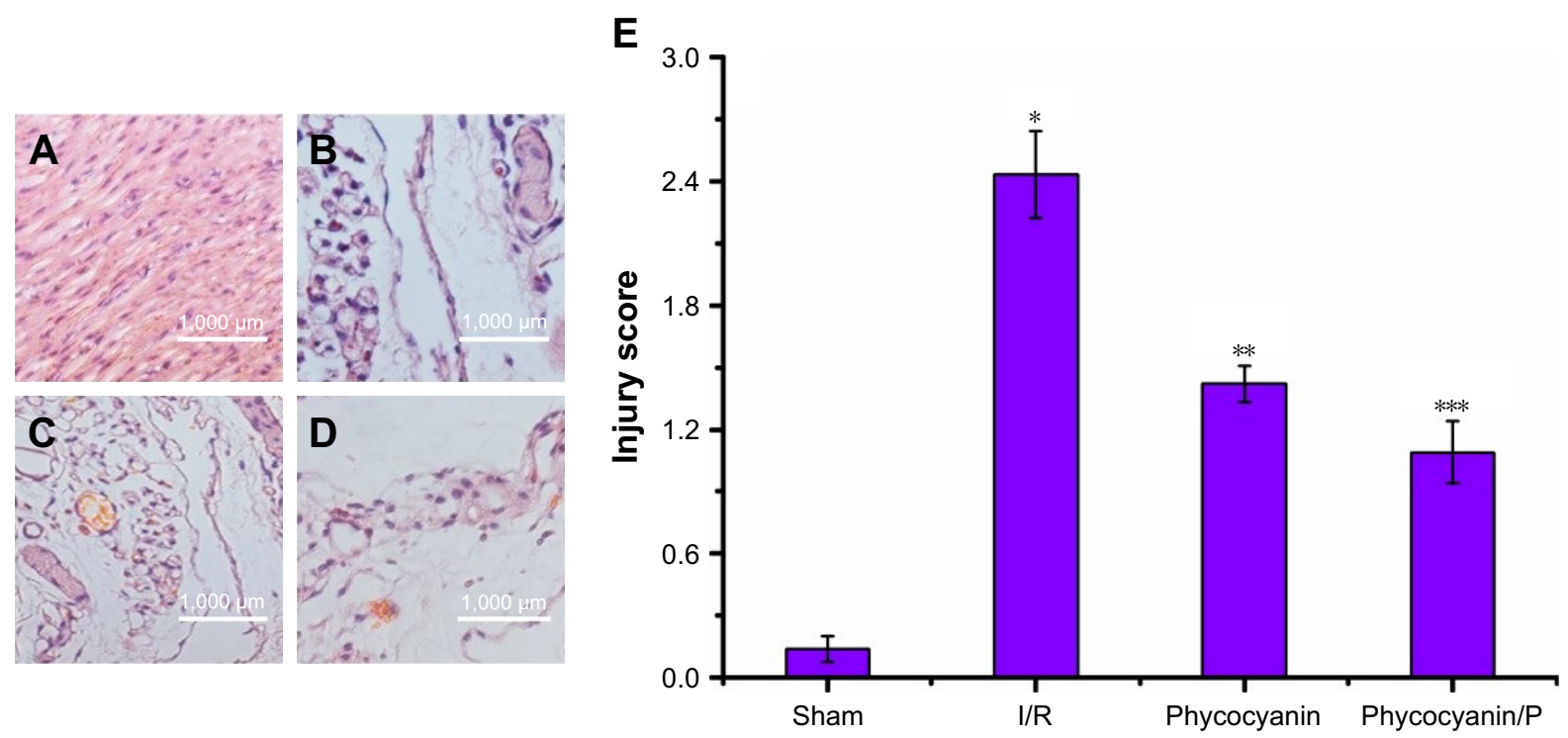

Figure 4 Histopathologic change of pancreatic islet tissues damage.

Notes: Light microscopy images $(\times 400)$ in Sham group (A), I/R group (B), phycocyanin group (C) and phycocyanin/PEG-b-(PG-g-PEI) group (D), respectively. Quantitative injury scores, expressed as the mean \pm SD, are shown in Figure $6(\mathbf{E})$. *Significant increase relative to the Sham group $(P<0.01)$. **Significant decrease relative to the $I / R$ group $(P<0.01)$. ***:Significant decrease relative to the I/R group $(P<0.01)$.

Abbreviation: PEG-b-(PG-g-PEI), poly(ethylene glycol)-b-(poly(L-glutamic acid)-g-polyethylenimine).
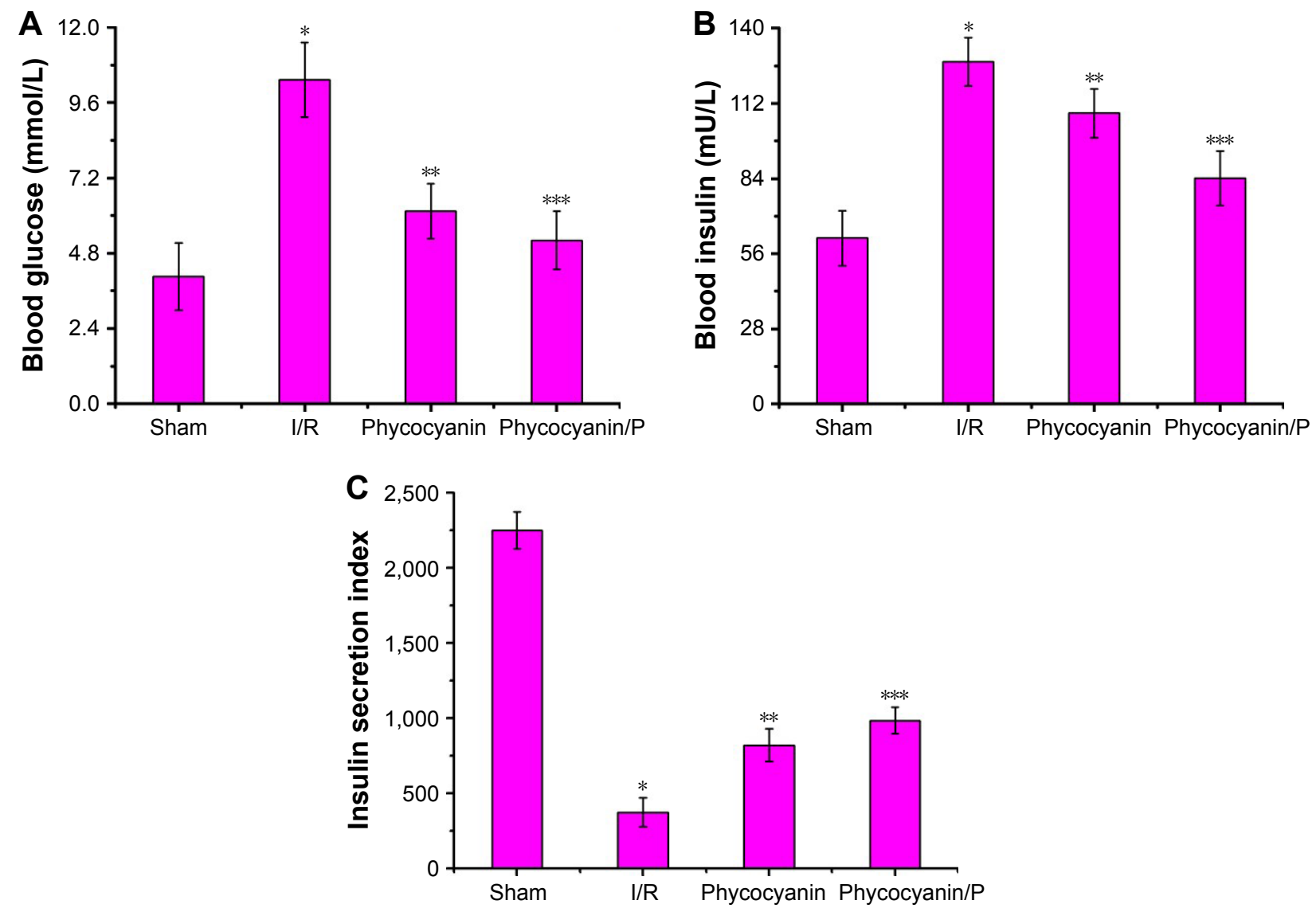

Figure 5 Blood glucose (A), blood insulin (B) and insulin secretion index (C) on HI/RIPIl for different groups of rats.

Notes: The blood of Sham, I/R, phycocyanin and phycocyanin/PEG-b-(PG-g-PEI) groups of rats were collected 12 hours after reperfusion and the activities of AST and ALT measured. Results are expressed as mean \pm SD. (A) *Significant increase from the Sham group $(P<0.0 \mathrm{I})$. $* *$ Significant decrease from the I/R group $(P<0.0 \mathrm{I})$. $* * *$ Significant decrease from the I/R group $(P<0.0 I)$. (B) *Significant increase from the Sham group $(P<0.0 \mathrm{I})$. **Significant decrease from I/R group $(P<0.0 \mathrm{I})$. ${ }^{*} *$ Significant decrease from $I / R$ groups $(P<0.0 \mathrm{I})$. (C) *Significant decrease from the Sham group $(P<0.0 \mathrm{I})$. ***ignificant increase from the I/R group $(P<0.0 \mathrm{I})$. *** Significant increase from the I/R group $(P<0.0 \mathrm{I})$. Abbreviations: I/R, ischemia/reperfusion; AST, aminotransferase; ALT, alanine aminotransferase; PEG-b-(PG-g-PEI), poly(ethylene glycol)-b-(poly(L-glutamic acid)-gpolyethylenimine). 

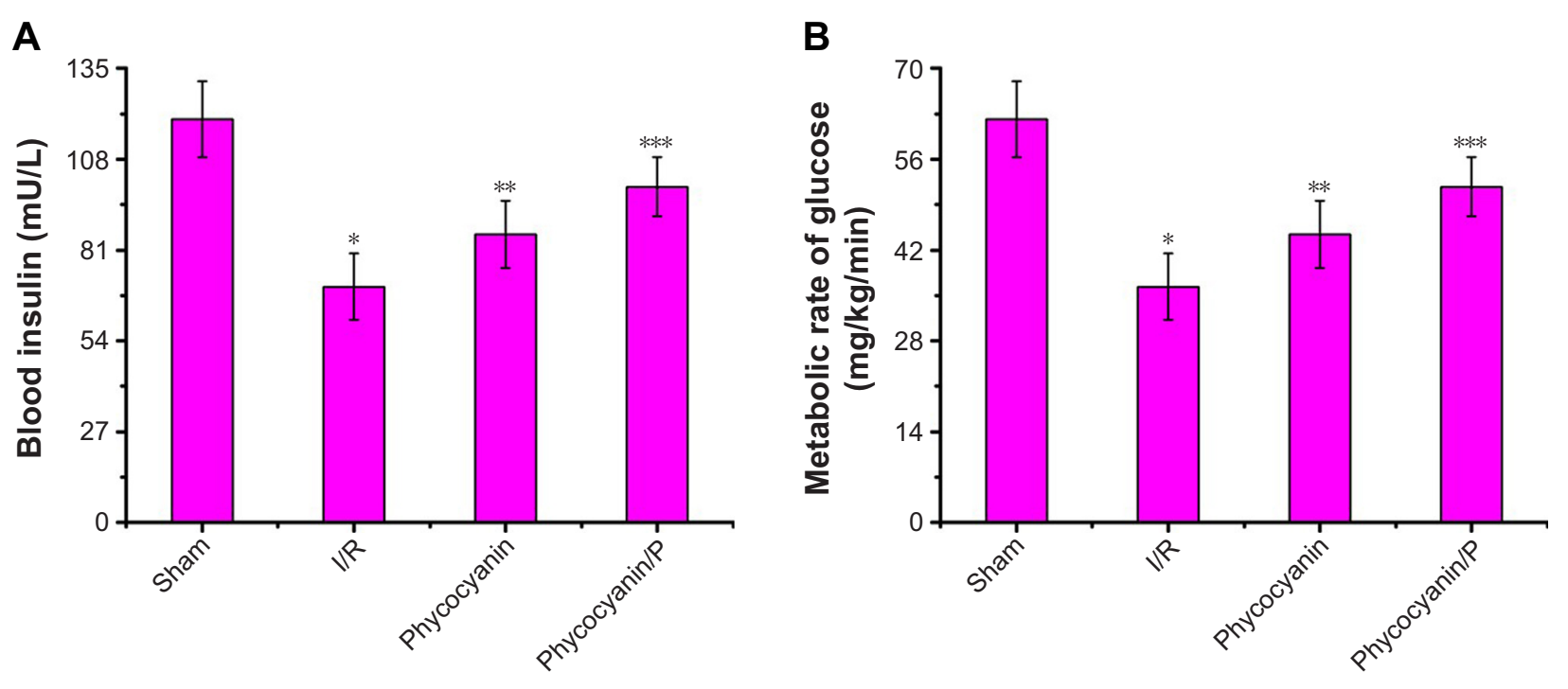

Figure 6 Blood insulin $(\mathbf{A})$ and metabolic rate of glucose $(\mathbf{B})$ on hyperglycemic clamp test.

Notes: The blood of Sham, I/R, phycocyanin and phycocyanin/PEG-b-(PG-g-PEI) groups of rats were collected after hyperglycemic clamp test and blood insulin level and metabolic rate of glucose measured. Results are expressed as mean \pm SD. (A) *Significant decrease from the Sham group $(P<0.01)$. **Significant increase from the I/R group $(P<0.01)$. *** Significant increase from the I/R group $(P<0.0 \mathrm{I})$. (B) *Significant decrease from the Sham group $(P<0.0 \mathrm{I})$. **Significant increase from the I/R group $(P<0.0 \mathrm{I})$. ****Significant increase from $\mathrm{I} / \mathrm{R}$ group $(P<0.01)$.

Abbreviation: PEG-b-(PG-g-PEI), poly(ethylene glycol)-b-(poly(L-glutamic acid)-g-polyethylenimine).

the Sham group $(P<0.01$; blood insulin: Sham group $119.95 \pm 11.27 \mathrm{mU} / \mathrm{L}, \mathrm{I} / \mathrm{R}$ group $70.18 \pm 9.84 \mathrm{mU} / \mathrm{L})$. Administration of phycocyanin increased blood insulin $(85.69 \pm 10.07$ $\mathrm{mU} / \mathrm{L}$ ) compared with blood insulin in the I/R group $(P<0.01)$. Administration of phycocyanin/P significantly increased blood insulin $(99.83 \pm 8.76 \mathrm{mU} / \mathrm{L})$ compared with blood insulin in the $\mathrm{I} / \mathrm{R}$ group $(P<0.01)$.

Metabolic rate of glucose was observed on hyperglycemic clamp test (Figure 6B) and was lower in the I/R group than in the Sham group $(P<0.01$; metabolic rate of glucose: Sham group $64.52 \pm 5.08 \mathrm{mg} / \mathrm{kg}^{-1} / \mathrm{min}^{-1}$, I/R group $22.43 \pm 3.45 \mathrm{mg} /$ $\left.\mathrm{kg}^{-1} / \mathrm{min}^{-1}\right)$. Administration of phycocyanin increased metabolic rate of glucose $\left(30.17 \pm 3.91 \mathrm{mg} / \mathrm{kg}^{-1} / \mathrm{min}^{-1}\right)$ compared with metabolic rate of glucose in the $\mathrm{I} / \mathrm{R}$ group $(P<0.01)$. Administration of phycocyanin/P significantly increased metabolic rate of glucose $\left(41.24 \pm 2.77 \mathrm{mg} / \mathrm{kg}^{-1} / \mathrm{min}^{-1}\right)$ compared with metabolic rate of glucose in the $\mathrm{I} / \mathrm{R}$ group $(P<0.01)$.

\section{SOD activity and MDA level}

Activity of SOD was measured after reperfusion for 12 hours (Figure 7A) and was less on $\mathrm{I} / \mathrm{R}$ group than in the Sham group $(P<0.01$; Sham group $40.17 \pm 3.08 \mathrm{U} / \mathrm{mL}, \mathrm{I} / \mathrm{R}$ group $10.03 \pm 1.81 \mathrm{U} / \mathrm{mL})$. Administration of phycocyanin increased SOD $(18.46 \pm 2.13 \mathrm{U} / \mathrm{mL})$ compared with SOD in the I/R group $(P<0.01)$. Administration of phycocyanin/P significantly increased SOD $(25.68 \pm 1.94 \mathrm{U} / \mathrm{mL})$ compared with SOD in the I/R group $(P<0.01)$.
Level of MDA was checked after reperfusion for 12 hours (Figure 7B) and was higher in the $\mathrm{I} / \mathrm{R}$ group than in the Sham group $(P<0.01$; Sham group $0.86 \pm 0.22 \mathrm{nmol} / \mathrm{mL}, \mathrm{I} / \mathrm{R}$ group $7.17 \pm 1.03 \mathrm{nmol} / \mathrm{mL})$. Administration of phycocyanin reduced MDA $(5.24 \pm 0.88 \mathrm{nmol} / \mathrm{mL})$ compared with MDA in the $\mathrm{I} / \mathrm{R}$ group $(P<0.01)$. Administration of phycocyanin/P significantly reduced MDA $(3.92 \pm 0.57 \mathrm{nmol} / \mathrm{mL})$ compared with MDA in the $\mathrm{I} / \mathrm{R}$ group $(P<0.01)$.

\section{Apoptosis evaluation}

Apoptosis of pancreatic islet tissue was measured after reperfusion for 12 hours (Figure 8 ) and was higher in the I/R group than in the Sham group $(P<0.01)$. Administration of phycocyanin reduced apoptosis of pancreatic islet tissue compared with apoptosis of pancreatic islet tissue in the I/R group $(P<0.01)$. Administration of phycocyanin/P significantly reduced apoptosis of pancreatic islet tissue compared with apoptosis of pancreatic islet tissue in the $\mathrm{I} / \mathrm{R}$ group $(P<0.01)$.

\section{ROS expression}

ROS expression of pancreatic islet tissue was measured after reperfusion for 12 hours (Figure 9) and was higher in the $\mathrm{I} / \mathrm{R}$ group than in the Sham group $(P<0.01)$. Administration of phycocyanin reduced ROS expression of pancreatic islet tissue compared with ROS expression of pancreatic islet tissue in the $\mathrm{I} / \mathrm{R}$ group $(P<0.01)$. Administration of phycocyanin/P significantly reduced ROS expression of 
A

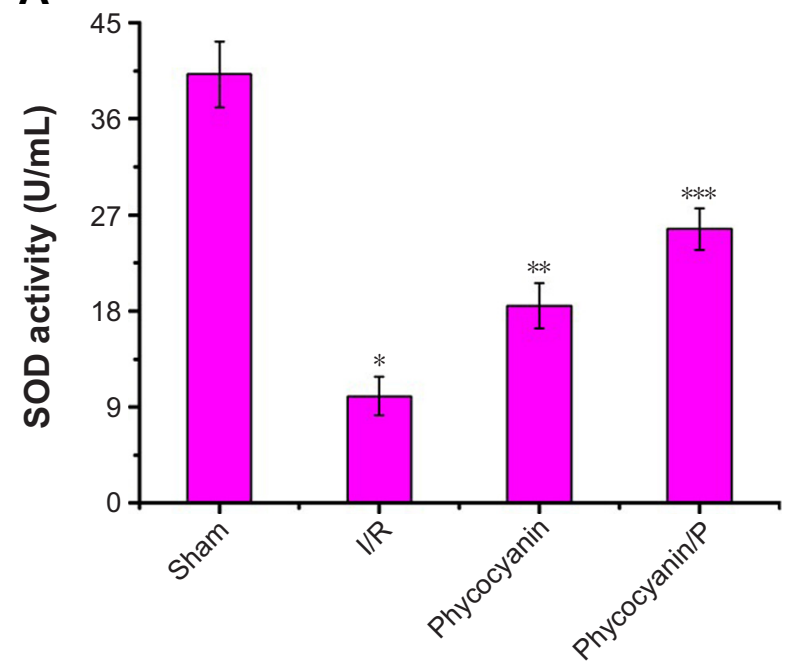

B

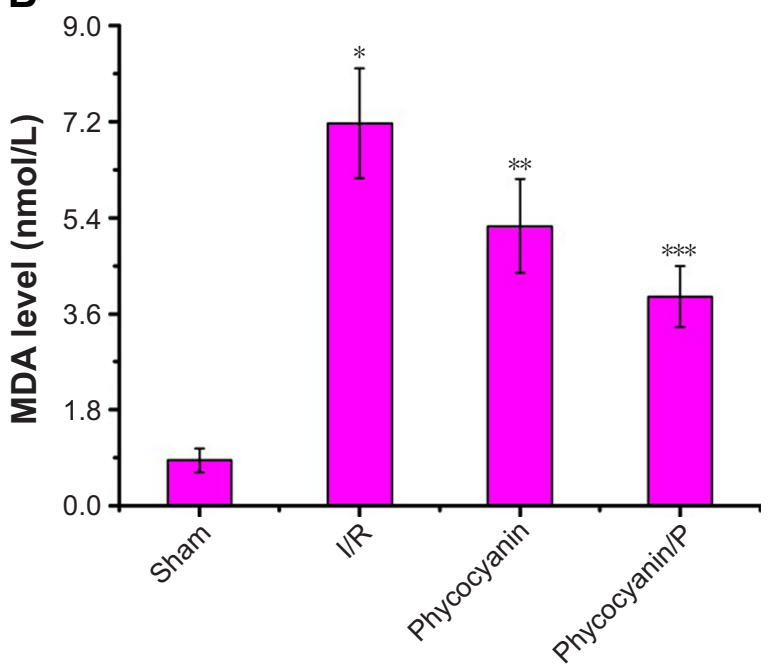

Figure 7 The activity of SOD and the level of MDA on HI/RIPII for different groups of rats.

Notes: The SOD activity and the MDA level of Sham, I/R, phycocyanin and phycocyanin/PEG-b-(PG-g-PEI) groups of rats were measured I2 hours after reperfusion. Results are expressed as mean \pm SD. (A) *Significant decrease from the Sham group $(P<0.0 \mathrm{I})$. **Significant increase from the I/R group $(P<0.0 \mathrm{I})$. ***Significant increase from the I/R group $(P<0.0 \mathrm{I})$. (B) *Significant increase from the Sham group $(P<0.0 \mathrm{I})$. **Significant decrease from the I/R group $(P<0.0 \mathrm{I})$. *** Significant decrease from the I/R group $(P<0.0 \mathrm{I})$. Abbreviations: I/R, ischemia/reperfusion; HI/RIPII, hepatic ischemia/reperfusion-induced pancreatic islets injury; MDA, malondialdehyde; PEG-b-(PG-g-PEI), poly(ethylene glycol)-b-(poly(L-glutamic acid)-g-polyethylenimine); SOD, superoxide dismutase.

pancreatic islet tissue compared with ROS expression of pancreatic islet tissue in the $\mathrm{I} / \mathrm{R}$ group $(P<0.01)$.

\section{Discussion}

Hepatic ischemia/reperfusion (HI/R) had been the topic of intense research and was a complex pathophysiological phenomenon. HI/RI could be divided into two distinct phases: first damage phase ( $<6$ hours) and second damage phase ( $>6$ hours). During the first damage phase intracellular production of xanthine oxidase and NADPH oxidase from hepatic cells was increased, and in the second damage phase reactive oxidant species (ROS) further augmented to aggravate liver and distant organs injury. ${ }^{1,37-39} \mathrm{In}$ addition, the effects of HI/RI were systemic and could cause functional and organic damage to multiple organs, such as circulatory failure, pulmonary edema, acute respiratory distress syndrome,
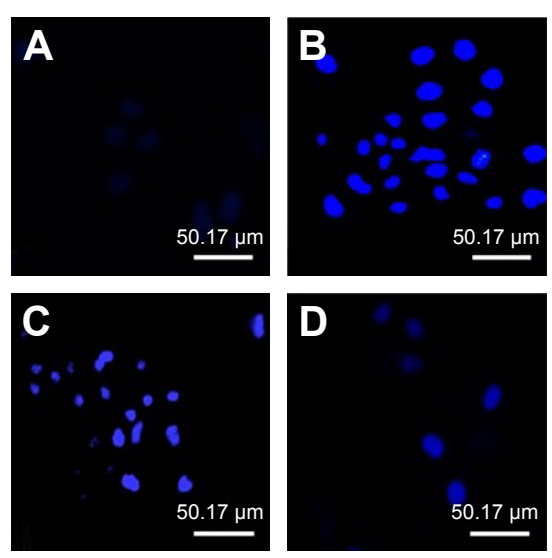

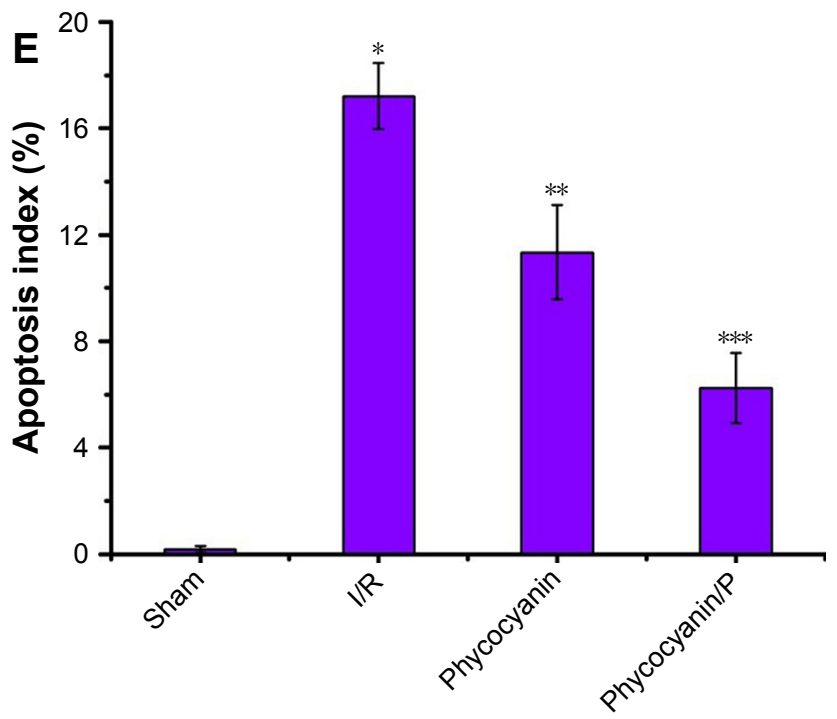

Figure 8 Apoptosis evaluation.

Notes: (A-E) The islet tissues of Sham, I/R, phycocyanin and phycocyanin/PEG-b-(PG-g-PEI) groups of rats were collected 12 hours after reperfusion and the apoptosis measured. Results are expressed as mean \pm SD. *Significant increase from the Sham group $(P<0.0 \mathrm{I})$. $* *$ Significant decrease from the I/R group $(P<0.0 \mathrm{I})$. $* * *$ Significant decrease from the $\mathrm{I} / \mathrm{R}$ group $(P<0.0 \mathrm{I})$.

Abbreviations: I/R, ischemia/reperfusion; PEG-b-(PG-g-PEI), poly(ethylene glycol)-b-(poly(L-glutamic acid)-g-polyethylenimine). 

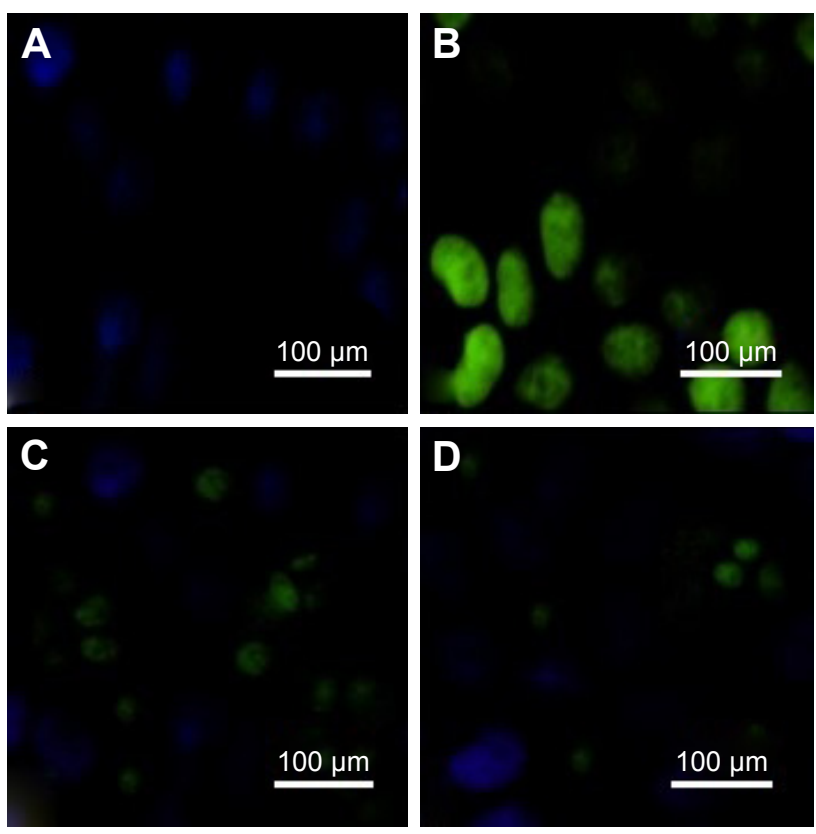

Figure 9 ROS expression.

Notes: (A-D) The islet tissues of Sham, I/R, phycocyanin and phycocyanin/PEG-b(PG-g-PEI) groups of rats were collected 12 hours after reperfusion and the ROS expression measured. The ROS expression is significantly higher in the $\mathrm{I} / \mathrm{R}$ group than in the Sham group; the ROS expression is lower in the phycocyanin group than in the I/R group; the ROS expression is significantly lower in the phycocyanin/P group than in the $\mathrm{I} / \mathrm{R}$ group.

Abbreviations: PEG-b-(PG-g-PEI), poly(ethylene glycol)-b-(poly(L-glutamic acid)-gpolyethylenimine); ROS, reactive oxygen species.

renal failure, islet damage. ${ }^{2}$ Previous literatures showed that HI/RI was mainly related to free radical damage, calcium overload, lipid peroxidation, microcirculatory disturbance of organs, release of inflammatory factors and respiratory eruption. ${ }^{2}$ Recently study had showed that during the first damage phase ROS activated Kupffer cells, increasing even further ROS as well as cytokine production, ${ }^{1}$ and in the second damage phase neutrophil recruitment and activation were involved. ${ }^{2}$ In the current study, we demonstrated that HI/RI could induce pancreatic islet damage via a remarkable augment of oxidative and apoptosis during the second damage phase. Furthermore, in this study we found that the blood glucose, blood insulin and insulin secretion index of Sprague Dawley rats were lower than those of the Sham group on HI/ RIPII, and in the hyperglycemic clamp test we found that the blood insulin in the I/R group was significantly lower than that in the Sham group, and the metabolic rate of glucose was also significantly lower than that in the Sham group. These results showed that the secretory function of pancreatic islet cells was obviously impaired in HI/RIPII.

Phycocyanin as deep-sea algae extract involved abundant functions and pharmacological action, such as antioxidant, anti-inflammatory, anticancer, anti-radiation, improved immunity role and anti-I/R injury. ${ }^{9-11}$ In our studies, we revealed that phycocyanin attenuated pancreatic islet damage after $\mathrm{HI} / \mathrm{RI}$ and enlarged islet functionality. However, phycocyanin treatment was limited due to its short plasma half-life and poor stability. Thus, dosing was extremely difficult and frequent injections were needed, which was inconvenient for patients and led to low compliance. ${ }^{12}$ Consequently, in order to solve this flaw we synthesized poly(ethylene glycol)- $b$ (poly(L-glutamic acid)-g-polyethylenimine) (PEG- $b$-(PG$g$-PEI)) (P) as potential phycocyanin carriers. We surveyed the function of phycocyanin and phycocyanin/P in the development and progression of HI/RIPII. Phycocyanin and phycocyanin/P preconditioning reduced liver and pancreatic islet injury, involving reduction of AST, ALT, MDA, apoptosis and ROS, as well as increased SOD. Moreover, this study reported a delivery system to increase both in vitro release and in vivo safety and efficacy of phycocyanin, administered as a subcutaneous abdominal injection, using encapsulation of a phycocyanin/P complex. Furthermore, PEG- $b$-(PG- $g$ PEI) could heighten blood half-life and bioactivity of phycocyanin to enhance its pharmacological treatment.

In conclusion, we authenticated that PEG- $b$-(PG- $g$-PEI) could increase the blood half-life of phycocyanin. In addition, phycocyanin/P could significantly reduce HI/RIPII and enlarged islet functionality via attenuating oxidative stress injury and apoptosis compared to free phycocyanin.

\section{Conclusion}

This study mainly synthesized PEG- $b$-(PG- $g$-PEI) to improve the bioactivity and short half-life of phycocyanin. In addition, it affirmed that phycocyanin and phycocyanin/PEG- $b$-(PG- $g$ PEI) pretreatment were both capable of attenuating HI/RIPII and enlarged islet functionality, and phycocyanin/PEG- $b$ (PG-g-PEI) pretreatment remarkably increased the effect.

\section{Acknowledgment}

This study was financially supported by the Science and Technology Planning Project of Jiaxing, Zhejiang Province (2017AY33076).

\section{Author contributions}

All authors contributed equally to this work and share equal responsibility as the first author. All authors contributed to data analysis, drafting or revising the article, gave final approval of the version to be published, and agree to be accountable for all aspects of the work.

\section{Disclosure}

This study was supported by the Zhejiang Province Nature Fund, Zhejiang Province (LY19B040003, Fei Tong). The authors report no other conflicts of interest in this work. 


\section{References}

1. Nastos C, Kalimeris K, Papoutsidakis N, et al. Global consequences of liver ischemia/reperfusion injury. Oxid Med Cell Longev. 2014; 2014(1):1-13.

2. Wu Y, Liu CM, Zhu JM. Effects of the second phase injury of hepatic ischemia-reperfusion on the secretion of pancreatic beta cells. J Clin Anesthesiol. 2009;25:252-254.

3. Chan KC, Lin CJ, Lee PH, et al. Propofol attenuates the decrease of dynamic compliance and water content in the lung by decreasing oxidative radicals released from the reperfused liver. Anesth Analg. 2008; 107(4):1284-1289.

4. Castro AP, Castro Junior MA, Lauz S, Facin E, Simões MJ, Fagundes DJ. The role of N-acetyl-cysteine in the lung remote injury after hepatic ischemia and reperfusion in rabbits. Acta Cir Bras. 2012;27(1):49-55.

5. Jaeschke H, Ramachandran A. Reactive oxygen species in the normal and acutely injured liver. J Hepatol. 2011;55(1):227-228.

6. Ge M, Chen C, Yao W, et al. Overexpression of Brg1 alleviates hepatic ischemia/reperfusion-induced acute lung injury through antioxidative stress effects. Oxid Med Cell Longev. 2017;2017(43):1-9.

7. Han SJ, Jang HS, Seu SY. Hepatic ischemia/reperfusion injury disrupts the homeostasis of kidney primary cilia via oxidative stress. Biochim Biophys Acta. 1863;2017:1817-1828.

8. Shen W, Ma X, Liu L. The effect of phycocyanin on the expression of iNOS in myocardial cells of type 2 diabetes mellitus in rats. Acta Academiae Medicinae Qingdao Universitatis (Chin). 2010;46: 283-285.

9. Bani-Sadr F, Teissiere F, Curie I, et al. Anti-infection prophylaxis after sexual assault. Experience of the Raymond Poincaré-Garches Hospital. Presse Med. 2001;30(6):253-258.

10. Pentón-Rol G, Marín-Prida J, Pardo-Andreu G, et al. C-Phycocyanin is neuroprotective against global cerebral ischemia/reperfusion injury in gerbils. Brain Res Bull. 2011;86(1-2):42-52.

11. Cao M, Lq X, Liu QZ. Protective effects of phycocyanin on myocardium in rats with acute myocardial ischemia reperfusion injuries. China Medical Herald. 2017;14:25-28.

12. Cy L, Li B, Yang P. Optimized preparation of novel c-phycocyanincarboxymethyl chitosan nanoparticles and its inhibitory effects on human cervical carcinoma HeLa cells proliferation. Chin J Cancer Biother. 2015;22:34-40.

13. He N, Sun H, Xu H, Dong X, Shao Z. Synthesis and characterization of PEG-b-(PG-g-PEI) for gene delivery. Nan Fang Yi Ke Da Xue Xue Bao. 2013;33(11):1643-1647. Chinese.

14. Tong F, Tang X, Luo L, et al. Sustained delivery of insulin-loaded block copolymers: Potential implications on renal ischemia/reperfusion injury in diabetes mellitus. Biomed Pharmacother. 2017;91:534-545.

15. Tong F, Dong B, Chai R, et al. Simvastatin nanoparticles attenuated intestinal ischemia/reperfusion injury by downregulating BMP4/COX-2 pathway in rats. Int J Nanomedicine. 2017;12:2477-2488.

16. Tong F, Tang X, Li X, Xia W, Liu D. The effect of insulin-loaded linear poly(ethylene glycol)-brush-like poly(l-lysine) block copolymer on renal ischemia/reperfusion-induced lung injury through downregulating hypoxia-inducible factor. Int J Nanomedicine. 2016;11:1717-1730.

17. Tong F, Zhang H. Poly (ethylene glycol)-block-brush poly (1-lysine) copolymer as an efficient nanocarrier for human hepatocyte growth factor with enhanced bioavailability and anti-ischemia reperfusion injury efficacy. Kidney Blood Press Res. 2017;42(3):495-508.

18. Tong F. Preparation of exenatide-loaded linear poly(ethylene glycol)brush poly(1-lysine) block copolymer: potential implications on diabetic nephropathy. Int J Nanomedicine. 2017;12:4663-4678.
19. Yang J, Wu R, Qiang X, et al. Human adrenomedullin and its binding protein attenuate organ injury and reduce mortality after hepatic ischemia-reperfusion. Ann Surg. 2009;249(2):310-317.

20. Li Y, Li T, Qi H, Yuan F. Minocycline protects against hepatic ischemia/ reperfusion injury in a rat model. Biomed Rep. 2015;3(1):19-24.

21. Yu Y, Li S, Wang Z, et al. Interferon regulatory factor-1 activates autophagy to aggravate hepatic ischemia-reperfusion injury via the P38/P62 pathway in mice. Sci Rep. 2017;7(1):43684.

22. He C, Myers MA, Forbes BE, Grützner F. Immunohistochemical analysis of pancreatic islets of platypus (Ornithorhynchus anatinus) and echidna (Tachyglossus aculeatus ssp.). J Anat. 2015;226(4):373-380.

23. Haffner SM, Kennedy E, Gonzalez C, Stern MP, Miettinen H. A prospective analysis of the HOMA model. The Mexico City Diabetes Study. Diabetes Care. 1996;19(10):1138-1141.

24. $\mathrm{Yh} \mathrm{H}, \mathrm{Pan} \mathrm{ZH}$. Methods for catheterization of carotid and jugular veins in rats. Chin J Lab Anim Sci. 2000;10:250-252.

25. Xiong HB, Sheng J, Ning Y. Technical improvement of jugular vein catheterization in rats. Xinjiang Med J. 2004;27:415.

26. Defronzo RA, Tobin JD, Andres R. Glucose clamp technique: a method for quantifying insulin secretion and resistance. Am J Physiol. 1979; 237(3):E214-E223.

27. Zhu M, Jia WP, Bao YQ. Establishment of hyperglycemic clamp technique. Chin J Diabetes. 2004;12:23-27.

28. Yang M, Wang YM, Meng QN. An experimental study of the impacts of magnetic fields on superoxide dismutase and malondialdehyde in rat pancreatic islet cells. Chin J Phys Med Rehab. 2012;34:733-736.

29. Chuvin N, Vincent DF, Pommier RM, et al. Acinar-to-ductal metaplasia induced by transforming growth factor beta facilitates $\mathrm{KRAS}^{\mathrm{G} 12 \mathrm{D}}$-driven pancreatic tumorigenesis. Cell Mol Gastroenterol Hepatol. 2017;4(2): 263-282.

30. Rankin MM, Wilbur CJ, Rak K, Shields EJ, Granger A, Kushner JA. $\beta$-cells are not generated in pancreatic duct ligation-induced injury in adult mice. Diabetes. 2013;62(5):1634-1645.

31. Goh SK, Bertera S, Olsen P, et al. Perfusion-decellularized pancreas as a natural 3D scaffold for pancreatic tissue and whole organ engineering. Biomaterials. 2013;34(28):6760-6772.

32. Westmoreland JJ, Wang Q, Bouzaffour M, Baker SJ, Sosa-Pineda B. Pdk1 activity controls proliferation, survival, and growth of developing pancreatic cells. Dev Biol. 2009;334(1):285-298.

33. Kristiansen KA, Jensen PE, Møller IM, Schulz A. Monitoring reactive oxygen species formation and localisation in living cells by use of the fluorescent probe CM-H(2)DCFDA and confocal laser microscopy. Physiol Plant. 2009;136(4):369-383.

34. Oparka M, Walczak J, Malinska D, et al. Quantifying ROS levels using CM-H DCFDA and HyPer. Methods. 2016;109:3-11.

35. Tan X, Zhang L, Jiang Y, et al. Postconditioning ameliorates mitochondrial DNA damage and deletion after renal ischemic injury. Nephrol Dial Transplant. 2013;28(11):2754-2765.

36. Doi K, Suzuki Y, Nakao A, Fujita T, Noiri E. Radical scavenger edaravone developed for clinical use ameliorates ischemia/reperfusion injury in rat kidney. Kidney Int. 2004;65(5):1714-1723.

37. Jaeschke H. Molecular mechanisms of hepatic ischemia-reperfusion injury and preconditioning. Am J Physiol Gastrointest Liver Physiol. 2003;284(1):G15-G26.

38. Smyrniotis V, Farantos C, Kostopanagiotou G, Arkadopoulos N. Vascular control during hepatectomy: review of methods and results. World J Surg. 2005;29(11):1384-1396.

39. Garcea G, Gescher A, Steward W, Dennison A, Berry D. Oxidative stress in humans following the Pringle manoeuvre. Hepatobiliary Pancreat Dis Int. 2006;5(2):210-214. 


\section{Supplementary materials}

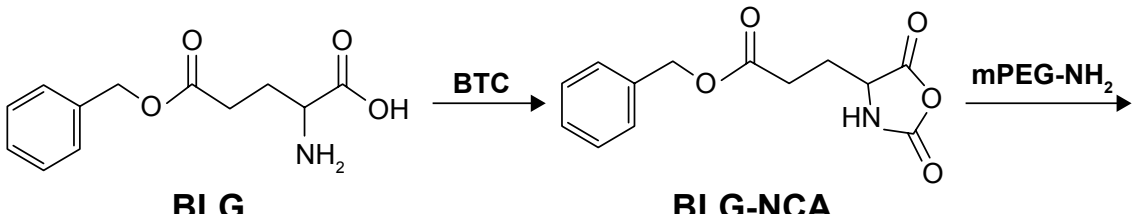

\section{BLG}

BLG-NCA
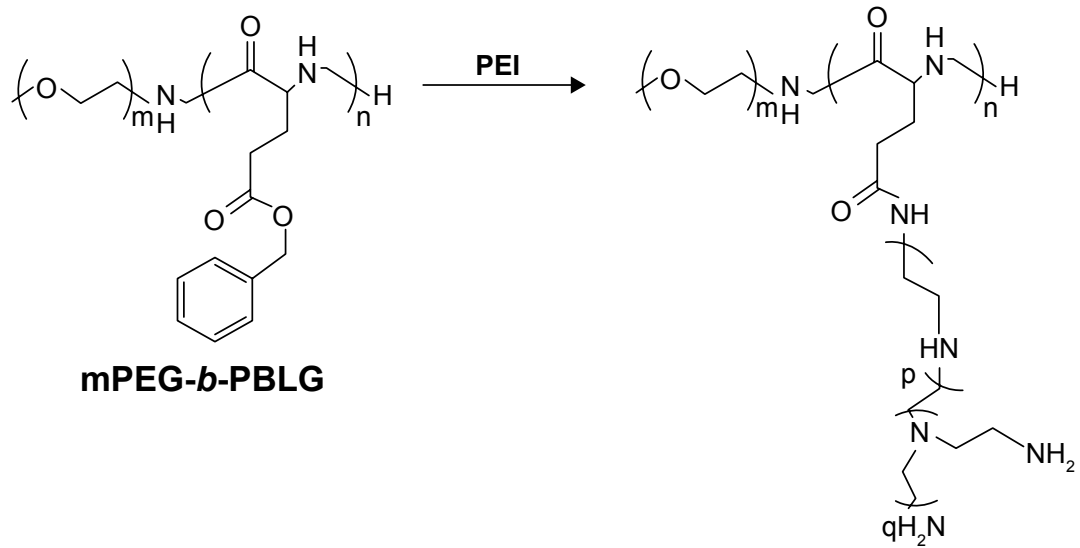

mPEG-b-(PG-g-PEI)

Figure SI The synthesis of PEG-b-(PG-g-PEI).

Abbreviations: BLG, $\gamma$-benzyl l-glutamate; BLG-NCA, $\gamma$-benzyl l-glutamate-N-carboxyanhydride; mPEG-NH${ }_{2}$, methoxy poly(ethylene glycol) amine; PBLG, poly( $\gamma$-benzyl I-glutamate); PEG-b-(PG-g-PEI), poly(ethylene glycol)-b-(poly(L-glutamic acid)-g-polyethylenimine). 
A
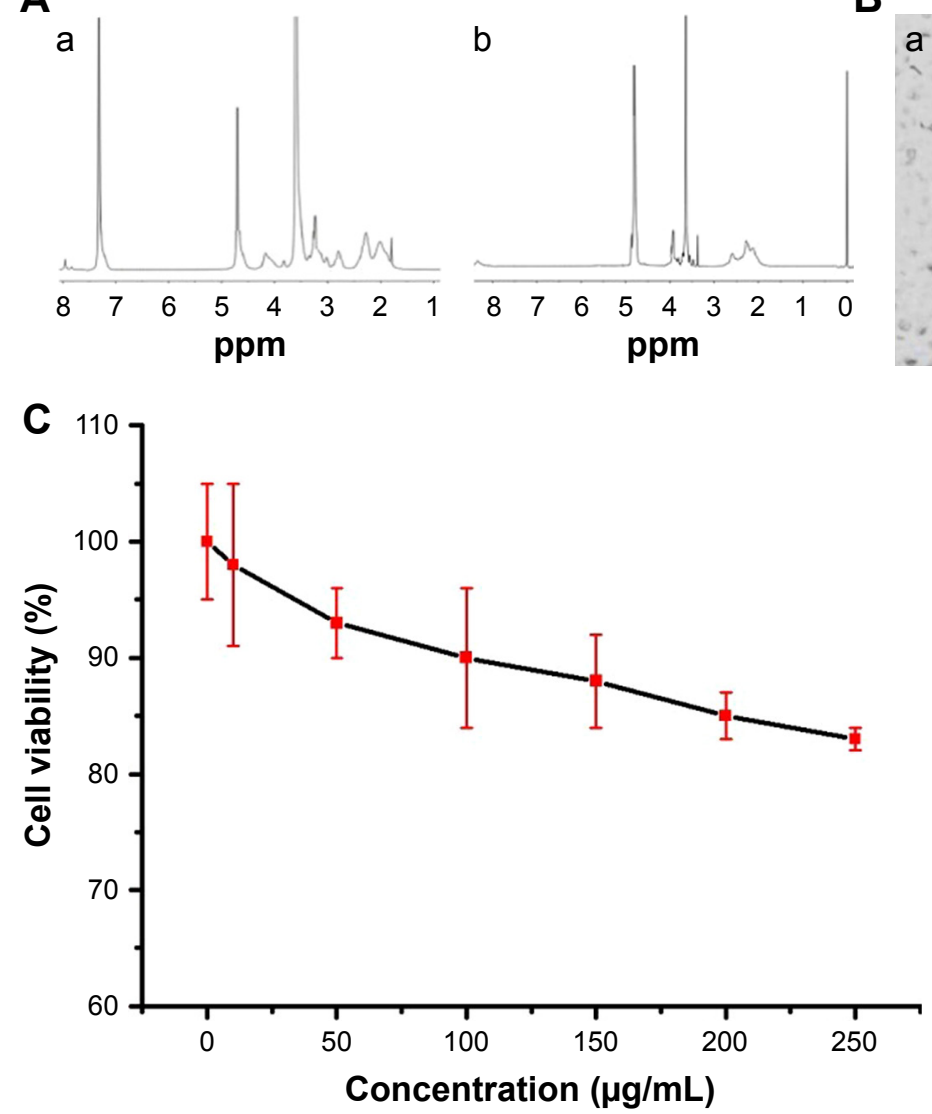

B
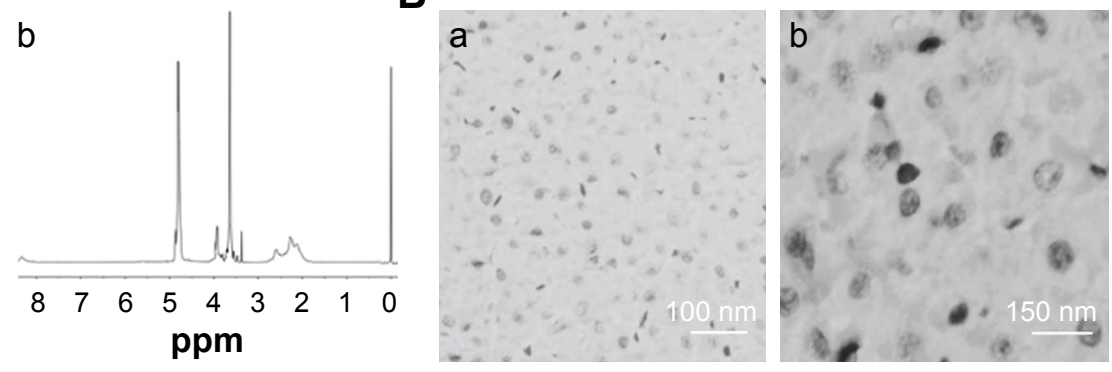

D

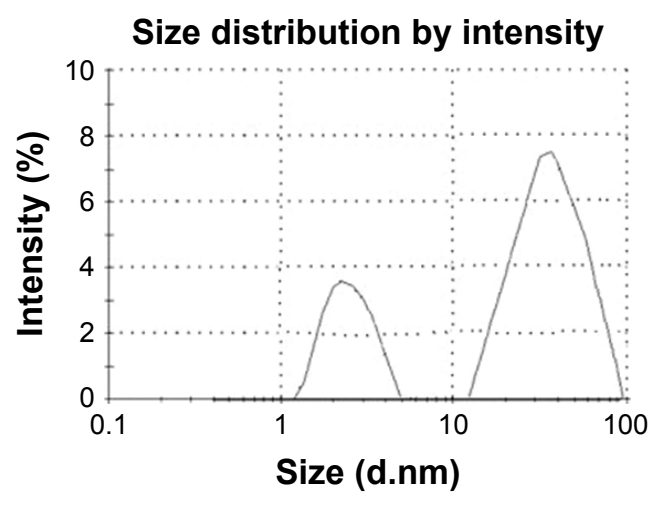

Figure S2 Characterization of PEG-b-(PG-g-PEI) and phycocyanin/PEG-b-(PG-g-PEI).

Notes: (A) 'H NMR spectra of PEG-b-PBLG (a) and PEG-b-(PG-g-PEI) (b); (B) TEM image of PEG-b-PBLG and phycocyanin/PEG-b-(PG-g-PEI); (C) cellular viability of HIT-TI 5 cells cultured with different concentrations of PEG-b-(PG-g-PEI); (D) diameter of PEG-b-(PG-g-PEI) (left) and phycocyanin/PEG-b-(PG-g-PEI) complexes (right) in PB. Abbreviations: 'H NMR, 'H-nuclear magnetic resonance; PBLG, poly( $\gamma$-benzyl I-glutamate); PEG-b-(PG-g-PEI), poly(ethylene glycol)-b-(poly(L-glutamic acid)-g-polyethylenimine); TEM, transmission electron microscopy.

\section{Publish your work in this journal}

The International Journal of Nanomedicine is an international, peerreviewed journal focusing on the application of nanotechnology in diagnostics, therapeutics, and drug delivery systems throughou the biomedical field. This journal is indexed on PubMed Central, MedLine, CAS, SciSearch ${ }^{\circledR}$, Current Contents ${ }^{\circledR} /$ Clinical Medicine,
Journal Citation Reports/Science Edition, EMBase, Scopus and the Elsevier Bibliographic databases. The manuscript management system is completely online and includes a very quick and fair peer-review system, which is all easy to use. Visit http://www.dovepress.com/ testimonials.php to read real quotes from published authors. 